\title{
Technical note: Reduced pulsation chamber vacuum at normal pulsation rate and ratio provides adequate prestimulation to induce oxytocin release and milk ejection while simultaneous milk flow is prevented
}

\author{
Anna-Lena Neuheuser, Claire Belo, and Rupert M. Bruckmaier ${ }^{1}$ \\ Veterinary Physiology, Vetsuisse Faculty, University of Bern, Bern, Switzerland 3012
}

\begin{abstract}
In the present study we investigated the milking characteristics and the oxytocin release in dairy cows milked after either manual prestimulation or a premilking period with pulsating liners at normal pulsation rate $(60)$ and ratio (60:40) while the pulsation chamber vacuum (PCV) was reduced to $20 \mathrm{kPa}$ to prevent the opening of the liners. During the milking trial with 8 cows the PCV reduction was started either before attachment (PCV-1) or immediately after attachment (PCV-2) of the teat cups. Milk yields, total milking times, average milk flows, peak flow rates, the duration of milk flow plateaus, and the duration of milk flow declines did not differ among the 3 treatments. Only the time to reach peak milk flow was prolonged when the vacuum reduction was started after teat cup attachment (PCV-2). In this treatment, milk flow $>200 \mathrm{~g} /$ min already occurred during the premilking period, resulting in bimodal milk flow curves. In 5 of the 8 cows, plasma oxytocin (OT) concentrations were measured from -2 min before the start of milking until 3 min of milking to compare the OT release in response to manual prestimulation and during PCV-1. In both treatments, OT increased similarly and remained elevated until the end of measurements. Consequently, the areas under the curve of OT concentrations did not differ between treatments. In conclusion, milking performance is similar if milking is performed after manual prestimulation or after normal pulsation at reduced PCV. To prevent milk flow during the prestimulation period, it is of crucial importance to start the reduction of the PCV before cluster attachment.
\end{abstract}

Key words: milking, dairy cow, oxytocin, pulsation, prestimulation

Received March 26, 2017.

Accepted July 9, 2017.

${ }^{1}$ Corresponding author: rupert.bruckmaier@vetsuisse.unibe.ch

\section{Technical Note}

A fundamental aim of prestimulation in the milking routine is the achievement of a continuous milk flow right from the start of milking. A timely release of oxytocin (OT) from the posterior pituitary (Lincoln and Paisley, 1982) is needed to fulfill this task. The plasma concentration of OT increases in response to tactile udder stimulation, which can be provided by the sucking calf, by manual teat stimulation, or by the movement of the teat cup liner of the milking machine (Bruckmaier and Blum, 1996). In response to OT, milk is shifted from the alveolar tissue into the cisternal cavities of the udder and thus becomes available for milk removal (Bruckmaier and Blum, 1998). The timing of prestimulation is crucial to prepare the udder adequately. The lag time from the start of a tactile stimulation can be less than $1 \mathrm{~min}$ in a full udder and much longer (up to $3 \mathrm{~min}$ ) in udders that are only partially filled (Bruckmaier and Hilger, 2001). The requirements for the intensity of stimulation are low, and even the attached teat cup without liner pulsation causes the release of OT; however, the increase of OT concentration can be less than $10 \mathrm{pg} / \mathrm{mL}$ (Weiss et al., 2003). In a 2-chamber milking unit the pulsation chamber is subjected to either vacuum (pulsation chamber vacuum; PCV) or atmospheric pressure by pulsation mostly at a frequency of around $60 \mathrm{~Hz}$. The claw vacuum that acts continuously beneath the teat provides the force to close the liner and to apply pressure on the teat end (Reinemann et al., 1994; Besier et al., 2016), whereas the role of the PCV is exclusively the cyclic opening (when applied) and closing (when ventilated) of the liner. It has been demonstrated that the regular liner pulsation is as effective for OT release as manual prestimulation (Bruckmaier and Blum, 1996). However, during normal pulsation the cyclic liner movement causes the removal of milk as long as milk is available in the cistern. If the milking is started in the absence of manual teat stimulation, the application of normal pulsation increases the probability of removal of cisternal milk before a successful milk ejection. Because 
the amount of cisternal milk is limited $(<20 \%$ of total milk), milk flow can be interrupted if the cisternal milk is completely removed before the OT-induced ejection of alveolar milk occurs. This results in bimodal milk flow curves (Bruckmaier and Blum, 1996). It has been shown that a reduced PCV at simultaneously high pulsation frequency of around $300 \mathrm{~Hz}$ as a prestimulation keeps the liner closed and that its vibration has a stimulatory effect on OT release and milk ejection (Worstorff et al., 1987; Weiss and Bruckmaier, 2005; Watters et al., 2015). We hypothesized that reduced PCV $(20 \mathrm{kPa})$ at a normal pulsation rate $(60 \mathrm{~Hz})$ and ratio (60:40) induces a sufficient OT release for milk ejection and provides a prestimulation comparable with manual prestimulation while keeping the liner closed and thus preventing milk removal during the prestimulation period.

Eight dairy cows - 4 Holstein and 4 Swiss Fleckvieh (Simmental $\times$ Red Holstein crossbreed) - from the Institute for Livestock Sciences, Research Station Agroscope (Posieux, Switzerland), were used for this study. The animals were in lactation mo 4 to 7 of their first to sixth lactation and had a daily milk production of 18 to $25 \mathrm{~kg}$ during the experimental period. Animals were kept in loose housing and were fed a partially mixed ration (grass silage, corn silage, soybean grist, and hay) ad libitum and concentrate according to the animal's individual production level.

Experimental milkings were performed with standard milking units (Cluster Uniflow 3 SS light; SAC, Kolding, Denmark) and standard liners (Uniflex, product no. 252.15.022; SAC) attached to a bucket milker. The system vacuum was $42 \mathrm{kPa}$. In the long pulse tubes a device was inserted that contained a valve. This valve was open under atmospheric pressure and at a vacuum up to $20 \mathrm{kPa}$ in the pulse tube. As soon as the vacuum in the pulse tube reached a threshold of $20 \mathrm{kPa}$ during the A-phase of pulsation the valve closed, and it opened again during the C-phase of the pulsation as soon as the vacuum in the pulse tube was below $20 \mathrm{kPa}$. Thus, the PCV could be limited to $20 \mathrm{kPa}$ after the device was manually switched on. As a consequence, the liners remained closed, although the alternating pulsation caused a minimal movement of the liner wall at a pulsation rate of $60 \mathrm{~Hz}$ and a pulsation ratio of 60:40. The valve opened automatically after a time period of $45 \mathrm{~s}$, the PCV increased to the level of the system vacuum, and milk removal started.

The present study included 2 experiments. Eight cows (4 Holstein and 4 Swiss Fleckvieh) were used for the first experiment. The whole udder was considered as the experimental unit. All cows were used in 3 different premilking treatments for a total of $5 \mathrm{~d}$. The sequence of the treatments was randomly allocated to each animal. Each premilking period lasted for $60 \mathrm{~s}$. The procedure included $10 \mathrm{~s}$ of manual teat cleaning as first teat contact for all treatments. In the treatment with manual prestimulation (ManSti), cleaning was followed by $45 \mathrm{~s}$ of teat and udder massage; cluster attachment then took place within $5 \mathrm{~s}$ of the completion of teat and udder massage. In premilking periods with reduced PCV, the $10 \mathrm{~s}$ of manual teat cleaning was followed by cluster attachment within $5 \mathrm{~s}$ of teat cleaning. The reduction of the PCV to $20 \mathrm{kPa}$ was performed either before cluster attachment $(\mathbf{P C V}-\mathbf{1})$ or within 2 $\mathrm{s}$ after cluster attachment (PCV-2). The ManSti and PCV-1 treatments were performed twice, whereas for technical reasons PCV-2 was performed only once. The milking took place during routine milking time in the evening (starting at $1600 \mathrm{~h}$ ) in the cows' usual milking environment. Before the start of the experiment, the cows were adapted to the new equipment during 2 milkings. Milk flow curves were recorded with a mobile milk flow recording unit (Lactocorder, WMB AG, Balgach, Switzerland). Milking characteristics were analyzed using the standard parameters of LactoPro software (version 5.2.0 beta 49; WMB AG). The parameters used were total milk yield, total milking time (time from start of milk removal until cluster detachment), average milk flow (calculated from total milk yield and total milking time), peak flow rate (maximal milk flow maintaining for at least $22 \mathrm{~s}$ ), time to reach peak flow rate, duration of plateau (time of a milk flow plateau between threshold slopes of $<800 \mathrm{~g} / \mathrm{min}^{2}$ and $>800 \mathrm{~g} /$ $\min ^{2}$ ), and duration of decline (after plateau until milk flow dropped below $0.2 \mathrm{~kg} / \mathrm{min}$ ). In addition, the occurrence of milk flow $>200 \mathrm{~g} / \mathrm{min}$ during the premilking period was recorded for PCV-1 and PCV-2 treatments.

Five cows (2 Holstein and 3 Swiss Fleckvieh) were used for the second experiment. The animals were assigned to 2 premilking treatments (ManSti and PCV-1) in random sequence. Each treatment was applied once in each cow during 1 evening milking (1600 h). Two days before the start of the experiment the animals were transferred into a tiestall barn and adapted to the new environment. An indwelling catheter (Cavafix Certo, $1.1 \times 1.7 \mathrm{~mm} / 16 \mathrm{G}$ and $32 \mathrm{~cm}$ with Splittocan; B. Braun Melsungen AG, Melsungen, Germany) with extension tubing (Heidelberger extension tubing; B. Braun Melsungen AG) was inserted into the right jugular vein $1 \mathrm{~d}$ before the start of the experiment. Premilking treatments (ManSti and PCV-1) were identical to those in experiment 1. Manual prestimulation included a 10-s manual teat cleaning followed by a teat and udder massage for $45 \mathrm{~s}$ before the teat cups were attached within $5 \mathrm{~s}$. During PCV-1 the $10 \mathrm{~s}$ of manual teat cleaning were followed by cluster attachment within $5 \mathrm{~s}$. The PCV was reduced to $20 \mathrm{kPa}$ immediately 
before attachment and lasted for $45 \mathrm{~s}$. Blood samples $(10 \mathrm{~mL})$ were taken from the catheter at $-2,-1$ (first tactile teat contact), $-0.5,0$ (immediately before the start of milking), 1, 2, and 3 min relative to the start of milk removal and treated with $200 \mu \mathrm{L}$ of Na-EDTA to prevent coagulation. Blood samples were placed on wet ice for a maximum of $1 \mathrm{~h}$ until centrifugation at 2,500 $\times g$ for $20 \mathrm{~min}$, and the obtained plasma was stored at $-20^{\circ} \mathrm{C}$ until analysis. Plasma OT concentration was determined by RIA as described by Schams (1983). The area under the curve (AUC) per minute of OT concentrations from the first tactile teat contact (time point -1 min) until 3 min of milking was calculated.

Results are presented as means \pm standard error of the mean. Statistical evaluations were performed using the MIXED procedure of SAS (version 9.4; SAS Institute Inc., Cary, NC), which is based on lsmeans. For both experiments, treatment effects on milking characteristics were analyzed with treatments set as fixed effects and the animals as repeated subjects. Differences between treatments were considered significant at $P<$ 0.05 using Bonferroni's $t$-test. Mean OT concentrations at each time point and AUC per minute of OT were calculated, and values were compared between the 2 treatments with Tukey's multiple comparison $t$-test $(P$ $<0.05)$.

The results of the milking characteristics of experiment 1 are shown in Table 1 . No differences in total milk yield, total milking time, average milk flow, peak flow rate, duration of plateau, and duration of decline were found among the 3 treatments $(P>0.05)$. The time to reach peak flow rate was prolonged in PCV-2 compared with ManSti and PCV-1 $(P<0.05)$.

A milk flow $>200 \mathrm{~g} / \mathrm{min}$ during the premilking treatments was recorded in $21 \%$ of milkings in PCV-1 and $88 \%$ of milkings in PCV-2. The course of milk flow during PCV reduction differed between individual milkings and already ceased during the premilking period (as shown for PCV-2 in Figure 1) or was maintained until PCV switched to the full level, when milk flow increased further.

In experiment 2 , the baseline OT concentrations were similarly low for ManSti and PCV-1 at 2 min before the start of milking (Figure 2). During both treatments OT increased within 1 min and reached similar concentrations at the start of milk removal. From 0.5 min before start of milking until 3 min of milking, OT levels of both treatments remained elevated over the baseline level $(P<0.05)$ and did not differ from each other at any of the recorded time points. The AUC per minute of OT was similar for both treatments (ManSti $=11.3$ $\pm 2.9 \mathrm{pg} / \mathrm{mL} ; \mathrm{PCV}-1=13.2 \pm 5.8 \mathrm{pg} / \mathrm{mL} ; P>0.05)$.

Manual teat stimulation, high-frequency vibration $(\sim 300 \mathrm{~Hz})$ stimulation, and the normal liner pulsation have been shown to cause comparable releases of OT to induce and maintain milk ejection during machine milking (Bruckmaier and Blum, 1996; Weiss et al., 2003; Watters et al., 2015). The present study showed that the pulsation at a reduced PCV caused only a reduced cyclic pressure difference on the liner while the liner remained closed. This treatment, although at the normal pulsation rate and ratio of the pulsator, induced an OT release similar to manual prestimulation. This finding confirms our previous finding that the requirements for the intensity of teat stimulation to induce OT release are minimal and that a threshold of only about $10 \mathrm{pg} / \mathrm{mL}$ needs to be surmounted to induce a full milk ejection (Weiss et al., 2003).

The adequacy of the pulsating closed liner for inducing milk ejection is also demonstrated by the recorded milking characteristics. Similar milk yields, machineon times, average milk flows, and peak flow rates did not differ between the treatments and thus indicate a successful milk harvest independent of the type of prestimulation (Baxter et al., 1950; Mayer et al., 1984; Bruckmaier and Blum, 1996). The requirement

Table 1. Milking characteristics of cows milked after $45 \mathrm{~s}$ of manual prestimulation (ManSti) and after a reduction of the pulsation chamber vacuum (PCV) for $45 \mathrm{~s}$ either before teat cup attachment (PCV-1) or immediately afterward $(\mathrm{PCV}-2)^{1}$

\begin{tabular}{lccc}
\hline Parameter & ManSti & PCV-1 & PCV-2 \\
\hline Total milk yield (kg) & $9.7 \pm 0.6$ & $9.2 \pm 0.6$ & $9.5 \pm 0.8$ \\
Total milking time (min) & $4.6 \pm 0.4$ & $4.5 \pm 0.4$ & $5.1 \pm 0.7$ \\
Average milk flow (kg/min) & $2.2 \pm 0.1$ & $2.2 \pm 0.2$ & $2.0 \pm 0.2$ \\
Peak flow rate (kg/min) & $3.5 \pm 0.2$ & $3.5 \pm 0.2$ & $3.6 \pm 0.4$ \\
Time until peak flow rate (min) & $0.7 \pm 0.1^{\mathrm{a}}$ & $0.9 \pm 0.1^{\mathrm{a}}$ & $1.4 \pm 0.2^{\mathrm{b}}$ \\
Duration of plateau (min) & $1.8 \pm 0.4$ & $1.5 \pm 0.3$ & $1.4 \pm 0.2$ \\
Duration of decline (min) & $2.2 \pm 0.2$ & $2.1 \pm 0.3$ & $2.4 \pm 0.5$ \\
\hline a,b Means with different superscripts indicate significant differences between treatments $(P<0.05)$. \\
${ }^{1}$ Each treatment started after 10 s of teat cleaning, and all milkings were performed under normal pulsation \\
rate (60) and ratio (60:40). The cluster in each treatment was attached during 5 s.
\end{tabular}




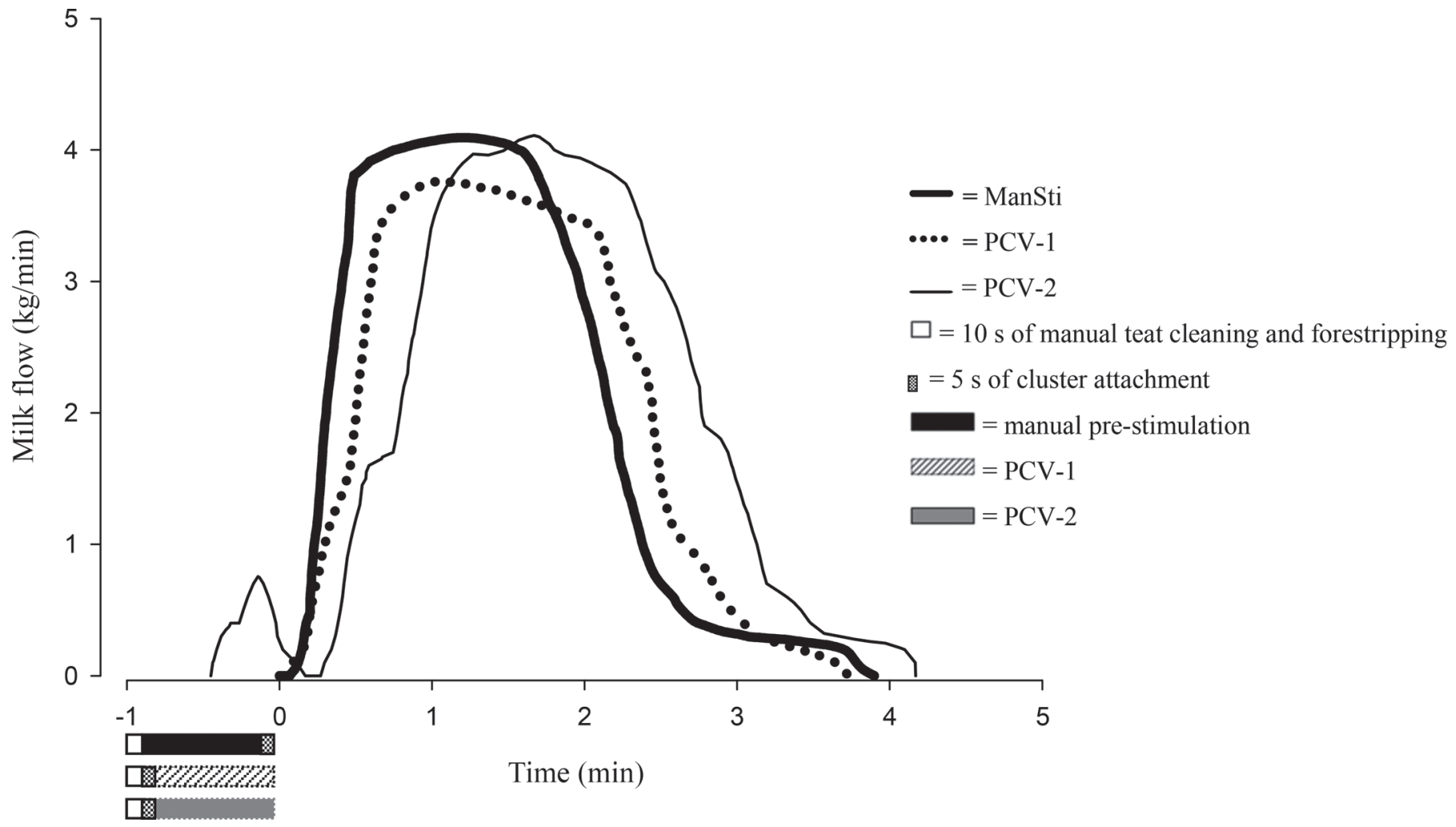

Figure 1. Milk flow curves in a single representative cow (no. 1577) during 3 premilking treatments and subsequent milkings. Premilking treatments were manual prestimulation (ManSti, $45 \mathrm{~s}$ ) or a closed liner pulsation $(45 \mathrm{~s})$. The liner closure was induced by pulsation chamber vacuum (PCV) reduction to $20 \mathrm{kPa}$ before cluster attachment (PCV-1) or within $2 \mathrm{~s}$ after cluster attachment (PCV-2). Every milking was performed with normal pulsation rate (60) and ratio (60:40). The premilking duration was $60 \mathrm{~s}$, including $10 \mathrm{~s}$ of teat cleaning and $5 \mathrm{~s}$ of cluster attachment in all treatments. During PCV-2 milk was removed, which resulted in a bimodal milk flow curve.

of adequate prestimulation is also fulfilled because the continuous liner closure during $45 \mathrm{~s}$ has shown stimulatory effect while considerable amounts of milk $(>200$ g) are not removed during this period in PCV-1. This treatment is comparable with the high-frequency liner vibration at reduced PCV that is also switched on be-

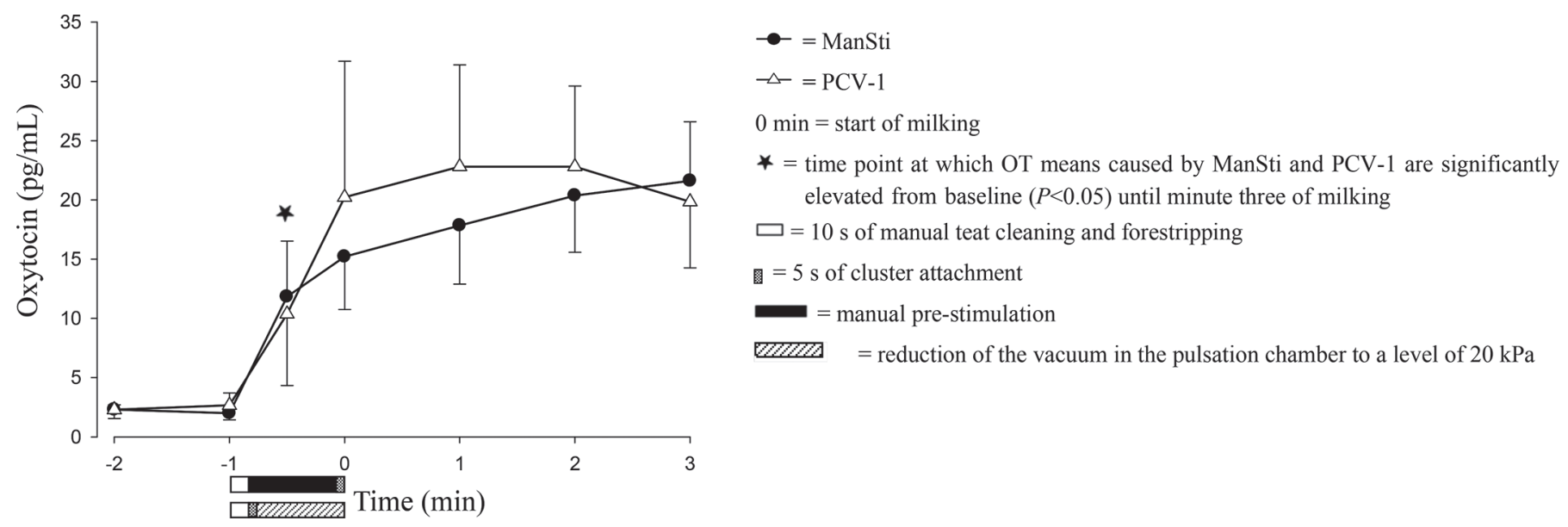

Figure 2. Oxytocin (OT) profiles during the premilking period and the first 3 min of milking. The premilking treatments consisted of manual prestimulation (ManSti, $45 \mathrm{~s}$ ) or a liner-closed phase induced by diminution of the vacuum in the pulsation chamber to a level of $20 \mathrm{kPa}$ before cluster attachment (PCV-1, $45 \mathrm{~s}$ ) with normal pulsation rate (60) and ratio (60:40). Both premilking treatments started after $10 \mathrm{~s}$ of manual teat cleaning. The premilking period in total lasted for $60 \mathrm{~s}$, including $5 \mathrm{~s}$ of cluster attachment. Error bars represent SEM. 
fore cluster attachment (Weiss and Bruckmaier, 2005; Watters et al., 2015). The high occurrence of milk flow in PCV-2 may be caused by a few cycles after teat cup attachment in which the liner completely opens until the vacuum reduction is activated within $2 \mathrm{~s}$ after attachment. Therefore, the teat gets sucked deeper into the teat cup during the few pulsation cycles until the PCV reduction becomes effective, which may cause a less effective liner closure at the teat end than in PCV-1. As a consequence, milk flow is less effectively prevented and cisternal milk is removed before milk ejection occurs in PCV-2. This results frequently in milk flow already during the prestimulation period. The full PCV application during this period of decreasing milk flow at the start of milk removal may cause negative effects such as early teat cup climbing or liner slips, leading to a higher risk of teat tissue damage and udder infections (Zecconi et al., 1992; Mein et al., 2003; Besier et al., 2016). In addition, the harvest of cisternal milk before milk ejection leads to a delayed increase of milk flow during the main milking phase, which was demonstrated by the increased time to reach peak milk flow observed in PCV-2. Nevertheless, milk flow in low quantities during PCV-1 had no negative influence on the main milk fraction removal.

The present study confirms that the stimulatory effect of $10 \mathrm{~s}$ of manual teat cleaning followed by $45 \mathrm{~s}$ of normal pulsation at reduced PCV does not differ from manual stimulation of the same duration. As the occurrence of milk flow appears more frequently in PCV-2 compared with $\mathrm{PCV}-1$, the reduction of $\mathrm{PCV}$ before teat cup attachment is required. As the released OT leads to similarly rapid and complete milk removal compared with after manual prestimulation, PCV reduction under normal pulsation is a suitable prestimulation in dairy practice. In addition, the reduced PCV allows an immediate attachment after a short teat cleaning while the milk removal and thus the occurrence of bimodal milk flow curves is prevented during this period.

\section{REFERENCES}

Baxter, E. S., P. M. Clarke, F. H. Dodd, and A. S. Foot. 1950. Factors affecting the rate of machine milking. J. Dairy Res. 17:117-127.

Besier, J., O. Lind, and R. M. Bruckmaier. 2016. Dynamics of teatend vacuum during machine milking: Types, causes and impacts on teat condition and udder health-A literature review. J. Appl. Anim. Res. 44:1263-1272.

Bruckmaier, R. M., and J. W. Blum. 1996. Simultaneous recording of oxytocin release, milk ejection and milk flow during milking of dairy cows with and without prestimulation. J. Dairy Res. 63:201208.

Bruckmaier, R. M., and J. W. Blum. 1998. Oxytocin release and milk removal in ruminants. J. Dairy Sci. 81:939-949.

Bruckmaier, R. M., and M. Hilger. 2001. Milk ejection in dairy cows at different degrees of udder filling. J. Dairy Res. 68:369-376.

Lincoln, D. W., and A. C. Paisley. 1982. Neuroendocrine control of milk ejection. J. Reprod. Fertil. 65:571-586.

Mayer, H., D. Schams, H. Worstorff, and A. Prokopp. 1984. Secretion of oxytocin and milk removal as affected by milking cows with and without manual stimulation. J. Endocrinol. 103:355-361.

Mein, G. A., D. M. Williams, and D. J. Reinemann. 2003. Effects of milking on teat-end hyperkeratosis: 1 . Mechanical forces applied by the teatcup liner and responses of the teat. Pages 114-123 in Proc. Natl. Mastitis Counc., Fort Worth, TX. National Mastitis Council, Verona, WI.

Reinemann, D. J., G. A. Mein, and K. Muthukumarappan. 1994. Forces applied to the bovine teat by the teatcup liner during machine milking. Report no. 94-D-052 presented at the XII CIGR World Congress and AGENG 94 Conference on Agricultural Engineering, Milano, Italy.

Schams, D. 1983. Oxytocin determination by radioimmunoassay. III. Improvement to subpicogram sensitivity and application to blood levels in cyclic cattle. Acta Endocrinol. (Copenh.) 103:180-183.

Watters, R. D., R. M. Bruckmaier, H. M. Crawford, N. Schuring, Y. H. Schukken, and D. M. Galton. 2015. The effect of manual and mechanical stimulation on oxytocin release and milking characteristics in Holstein cows milked 3 times daily. J. Dairy Sci. 98:1721-1729.

Weiss, D., and R. M. Bruckmaier. 2005. Optimization of individual prestimulation in dairy cows. J. Dairy Sci. 88:137-147.

Weiss, D., A. Dzidic, and R. M. Bruckmaier. 2003. Effect of stimulation intensity on oxytocin release before, during and after machine milking. J. Dairy Res. 70:349-354.

Worstorff, H., A. Prediger, G. Karch, and H. Mayer. 1987. Function theory of mechanical prestimulation of dairy cows by vibration stimulation. Milchwissenschaft 42:353-356.

Zecconi, A., J. Hamann, V. Bronzo, and G. Ruffo. 1992. Machineinduced teat tissue reactions and infection risk in a dairy herd free from contagious mastitis pathogens. J. Dairy Res. 59:265-271. 